\title{
Article \\ Cannabis Stocks Returns: The Role of Liquidity and Investors' Attention via Google Metrics
}

\author{
Stephanos Papadamou ${ }^{1}\left(\mathbb{D}\right.$, Alexandros Koulis ${ }^{2}$, Constantinos Kyriakopoulos ${ }^{3}$ and Athanasios P. Fassas ${ }^{4, *(\mathbb{D}}$ \\ 1 Laboratory of Economic Policy and Strategic Planning, Department of Economics, University of Thessaly, \\ 38333 Volos, Greece; stpapada@uth.gr \\ 2 Department of Regional Development, Ionian University, 31100 Lefkada, Greece; akoulis@ionio.gr \\ 3 Department of Mathematics, National and Kapodistrian University of Athens, 15772 Athens, Greece; \\ kkiriak@aueb.gr \\ 4 Department of Accounting and Finance, University of Thessaly, 41500 Larissa, Greece \\ * Correspondence: afassas@uth.gr; Tel.: +30-2410684329
}

Citation: Papadamou, Stephanos,

Alexandros Koulis, Constantinos Kyriakopoulos, and Athanasios P. Fassas. 2022. Cannabis Stocks Returns: The Role of Liquidity and Investors' Attention via Google Metrics. International Journal of Financial Studies 10: 7. https:// doi.org/10.3390/ijfs10010007

Academic Editor: Sabri Boubaker

Received: 18 November 2021

Accepted: 30 December 2021

Published: 5 January 2022

Publisher's Note: MDPI stays neutral with regard to jurisdictional claims in published maps and institutional affiliations.

Copyright: (c) 2022 by the authors. Licensee MDPI, Basel, Switzerland. This article is an open access article distributed under the terms and conditions of the Creative Commons Attribution (CC BY) license (https:// creativecommons.org/licenses/by/ $4.0 /)$.

\begin{abstract}
This paper studies one of the most popular investment themes over recent years, investing in the cannabis industry. In particular, it investigates relationships between investor attention, as proxied by Google Trends, and stock market activities, i.e., return, volatility, and liquidity. To this end, in the empirical analysis we study how liquidity and investors' attention affect the return dynamics of an investment in cannabis stocks by augmenting the three-factor Fama-French model. In addition, we use a vector autoregressive approach and the impulse response function to measure shock transmission between the variables under consideration. Our empirical findings show that there is a statistically positive relationship between cannabis stock returns and liquidity. We also find that increased investors' attention results in higher returns.
\end{abstract}

Keywords: cannabis stocks; Google metrics; investors' attention; liquidity

\section{Introduction}

As cannabis is being legalized in a growing number of countries, investing in the cannabis industry has gained significant momentum over the past few years. Nevertheless, the respective academic literature is still rather limited (see Weisskopf (2020) and the references therein). This paper contributes to this strand of literature by employing a generalized autoregressive conditional heteroscedasticity $(\mathrm{GARCH})$ model to study the relationship between investors' attention, liquidity, and cannabis stock returns. The assetpricing results indicate a positive relationship between returns and liquidity and investors' attention.

The cannabis market is a relatively new market driven by medicinal and recreational businesses. According to Bahji and Stephenson (2019), in many U.S. states-including Colorado and California-cannabis has been legalized for recreational (and often medicinal use) andmany countries, such as Uruguay, Spain, the Netherlands Canada, etc., have passed or are in the process of passing laws allowing the use of cannabis for medicinal and/or recreational purposes. This process is not without risks for the investors (Parker et al. 2019). Market and pricing risks, legal risk including banking and insurance, supply chain and funding risk may undermine the investment in these stocks in the future. According to the findings of Andrikopoulos et al. (2021), herding is observed for all Canadian listed stocks across all markets and sectors in contrast with the US, where herding is a relatively limited phenomenon. This is attributed to the various stages of legalization in the two countries and to the type of legalization, which in the case of Canada removes many of the risks mentioned above, prominently the legal one. However, despite the lack of herding in the US, the benefits of including cannabis stocks in a portfolio are demonstrated by Weisskopf (2020). Cannabis stocks display low correlations and beta coefficients to 
stock markets, but also with other sin markets (gambling tobacco and alcohol stocks) and cryptocurrencies. Moreover, due to their high volatility and returns, their addition will benefit the portfolio for diversification and yield enhancement purposes.

As far as the positioning of the paper goes, it contributes to three strands of empirical literature. The first strand investigates the performance of cannabis stocks; the respective literature is very limited but has been growing recently (see Chen et al. (2021) for a comprehensive review). The second strand relates to an emerging literature that studies the impact of investors' attention on asset market microstructure and asset price dynamics (see Papadamou et al. (2020) for a relevant discussion). A direct measure of investor attention is the aggregate search frequency in Google, but other measures such as media coverage also attract investor attention (Akhtaruzzaman et al. 2021). Finally, our paper provides a contribution to the literature on liquidity, which investigates the dynamic relationship between the asset returns and the dynamic evolution of liquidity.

Against this background, the current study extends this literature, by investigating the relationship between investors' attention and stock returns in the cannabis sector. Furthermore, we expand the research to an emerging, extremely popular, segment of equity markets to obtain information regarding how liquidity affects stock returns. Therefore, this paper fills the gap in existing literature by studying for the first time cannabis stocks in such a fashion. In particular, we form two main research questions to be answered: (1) Does liquidity affect stock returns in an alternative market, such as the cannabis sector? (2) Does investors' attention as proxied by Google's search volume index relates to cannabis stock returns?

The empirical results provide interesting findings as they make a statistically significant positive contribution of liquidity measure on cannabis stock returns. Moreover, this type of stock is also significantly influenced by investors' attention measured by Google search activity. Since internet users commonly use a search engine to collect information, and Google continues to be the dominant search engine worldwide, the search volume reported by Google can be considered to be representative of the internet search behavior of the general population.

The rest of the paper proceeds as follows Section 2, concisely reviews the relevant literature. Section 3 describes the methodology employed, while Section 4 includes the empirical results and their analysis. Section 5 contains the concluding remarks.

\section{Related Literature}

This study contributes to the cannabis-related literature by testing the return-liquidity relationship for three popular cannabis stocks. Liquidity is one of the most important and desired factors that investors are looking into when they plan to invest. A pioneer study by Boubaker et al. (2019) highlights that less readable annual reports by companies are associated with lower stock liquidity. Illiquidity (obviously the opposite of liquidity) erodes profits and exacerbates losses because in illiquid markets the cost of buying and selling any investment increases with the so-called slippage (broadly defined as the difference between offer and bid price). Since a portfolio is constituted by individual investments, the merits of portfolio diversification are compromised when illiquid investments are included. Numerous studies (indicatively, among others, Amihud and Mendelson 1986; Brennan and Subrahmanyam 1996; Liu 2006; Hasbrouck 2009) have focused on the importance of liquidity in markets. Although many liquidity measures have been proposed, the one proposed by Amihud (2002), defined as the ratio of stock's absolute daily return and its trading volume in order to discover that positive illiquidity-return relationship persist for a long sample period from 1964 to 1997, gained growing popularity due to its clarity and ease of use. This measure was employed by Acharya and Pedersen (2005) to show that a stock's expected return is significantly influenced by the covariance between stock liquidity and market return or market liquidity and by Amihud et al. (2015) to explore the illiquidity premium in global markets. The fact that liquidity risk is more significant in emerging than developed markets was confirmed by Lee (2011) and Lang et al. (2012) 
showed that firms in these markets suffer lower liquidity and higher transaction costs. Chiang and Zheng (2015) performed panel regressions on monthly data for 20 years to test the relation between expected excess stock returns and illiquidity risk in G7 markets and found that returns are positively correlated with market illiquidity risk but are negatively correlated with the innovation of firm-level illiquidity. On a broader scale, by investigating the market liquidity and efficiency of the merger between the Surabaya Stock Exchange and the Jakarta Stock Exchange, Yang and Pangastuti (2016) discovered that greater market efficiency was achieved by non-financial and large cap companies. On the other hand, in their analysis of liquidity sensitivity of stock returns in the Norwegian stock market over the period 1983-2015, Leirvik et al. (2017) found no significant relationship between returns and market liquidity. Also, the fact that predictability decreases with high market liquidity was showed by studying the liquidity of 456 different currencies in the newly developed cryptocurrency market. Furthermore, Kyriazis and Prassa (2019) showed a relationship between liquidity and state of the market with cryptocurrencies becoming more liquid during stressed periods.

Another factor that seems to interact with the liquidity and returns of the stocks in the cannabis market is the daily investors' attention to this market as manifested in various search engines. The value of the data collected through various digital platforms for predictive purposes is becoming increasingly important mainly due to their richness, depth, versatility, and timeliness of retrieved information. Nowadays the various search queries play crucial role in forming decisions and these in turn are precursors for various actions. Thus, these data usually affect various important variables in many disciplines. Especially the data collected from Google (through the Google Trends application) have been used for studying a range of phenomena: the spread of flu (Ginsberg et al. 2009; Polgreen et al. 2008), the effect of COVID-19 on financial markets (Papadamou et al. 2021), the effect of macroeconomic policies on stock market dynamics (Poutachidou and Papadamou 2021), the prediction of the election outcomes (Metaxas and Mustafaraj 2012; Polykalas et al. 2013), the prediction of aggregate consumer behavior (Carrière-Swallow and Labbé 2013), and the prediction of various economic indicators (Choi and Varian 2012). Additionally, the use of query data has proven very useful in many areas of finance such as in corporate finance where they have been used to predict investors' behavior around corporate earnings announcements (Drake et al. 2012) or investors' bias in equity holdings (Mondria et al. 2010). The first use of Google query data to construct an index for the prediction of stock market movements was made by Da et al. (2011). Since then, attention was focused on the way the data impact the asset prices, volume, and volatility (Joseph et al. 2011; Drake et al. 2012; Vlastakis and Markellos 2012; Smith 2012; Preis et al. 2013; Vozlyublennaia 2014; Da et al. 2015; Ding and Hou 2015; Dimpfl and Jank 2016; Goddard et al. 2015; Chronopoulos et al. 2018; Padungsaksawasdi et al. 2019).

\section{Materials and Methods}

Our dataset spans from 3 January 2017 to 30 October 2020 (yielding 999 daily observations) and includes three cannabis stocks: Aurora Cannabis Inc. (ACB), Edmonton, Canada, Canopy Growth Corp. (CGC), Smiths Falls, Canada and Cronos Group Inc. (CRON), Toronto, Canada. These stocks have been selected due to their strong dominant position in the industry. In particular, ACB is a dominant player in the global marijuana trade, listed in NYSE with market capitalization in 2020 around USD1.54 billion. Also, both CGC and CRON are major's players in the industry, listed in NASDAQ with market capitalizations of USD 11.23 billion and USD 2.2 billion, respectively. The North American Marijuana Index (NAMMAR) tracks the performance of a basket of North American publicly listed companies with significant business activities in the marijuana industry. The index is calculated as a gross total return index in CAD adjusted quarterly.

Liquidity is unobservable, therefore it is not universally definable and measurable. A comprehensive review of the various approaches to liquidity definition can be found in Assoil et al. (2021) and the references therein. In this paper, we follow Danyliv et al. 
(2014) who develop an easy-to-calculate liquidity ratio that enables comparisons of liquidity between different securities and markets, and it is calculated as follows:

$$
\operatorname{LIX}_{\mathrm{t}}=\ln \left(\frac{\mathrm{V}_{\mathrm{t}} \mathrm{P}_{\text {close }, \mathrm{t}}}{\mathrm{P}_{\text {High }, \mathrm{t}}-\mathrm{P}_{\text {Low }, \mathrm{t}}}\right)
$$

in which, $V_{t}$ is the number of shares traded in day $t$, and $P_{\text {close }}, P_{\text {high }}$ and $P_{\text {low }}$ are the closing, the highest and the lowest price of the day $t$ respectively. This definition of liquidity takes the perspective of investors, who relate liquidity with the amount of money they can invest without significantly moving market prices. The log transformation leads to a ratio between 5 (for the least liquid assets) and about 10 (for the most liquid assets). The employed liquidity measure has two major advantages: it is extremely easy to calculate because all the information required is readily available and it eliminates the currency value, thus different securities from different markets can be directly compared (Danyliv et al. 2014). Its main disadvantage is that the LIX measure cannot be calculated when the highest and the lowest price are equal (and thus the denominator is equal to zero) and/or when the number of shares traded is equal to zero (and thus the nominator is equal to zero). In our empirical analysis, the choice of the stocks under examination is based on the criteria that the estimated liquidity measure is non-zero, suggesting that actual trading occurs every day in our sample period. For the Google Trends indicator, we construct an indicator that equals to $\log (\mathrm{e}+$ Google Trends metric value $)$ similarly to Eckstein and Tsiddon (2004). The index score is dynamic, as the size of previous search volume becomes bigger or smaller relative to new data.

Our empirical analysis is based on the three-factor Fama and French (1993) model augmented initially with the liquidity measure as follows:

$$
\begin{aligned}
\mathrm{R}_{\mathrm{it}}-\mathrm{r}_{\mathrm{t}}=\beta_{\mathrm{i} 0}+\beta_{\mathrm{i} 1} \mathrm{R}_{\text {NAMMARt }} & +\beta_{\mathrm{i} 2}\left(\mathrm{R}_{\mathrm{Mt}}-\mathrm{r}_{\mathrm{t}}\right)+\beta_{\mathrm{i} 3} \mathrm{HML}_{\mathrm{t}}+\beta_{\mathrm{i} 4} \mathrm{SMB}_{\mathrm{t}}+\beta_{\mathrm{i} 5} \% \mathrm{LIX}_{\mathrm{t}} \\
& +\beta_{\mathrm{i} 6} \% \mathrm{LIX}_{\mathrm{t}-1}+\mathrm{u}_{\mathrm{it}}
\end{aligned}
$$

in which, $R_{i t}$ is the daily return of stock $i(i=A C B, C G C, C R O N)$ on day $t, r_{t}$ is the risk-free rate of return, $R_{\text {NAMMAR }}$ is the daily return of the Marijuana Index, $R_{M}$ is the return of the market, SMB is the average return of the small-capitalized portfolios minus the average return of the large-capitalized portfolios, HML is the average return of the value portfolios minus the average return of the growth portfolios, while \%LIX is the first logarithmic difference of the liquidity measure (LIX) and $\mathrm{u}_{\mathrm{it}}$ is the error term. HML, SMB and Market risk premium are taken from French's website, while stock prices and volumes were retrieved from Investing.com. The error term $u_{i t}$ follows a GARCH $(1,1)$ model such that:

$$
u_{t} \mid \Omega_{t-1}=\sqrt{h_{t}} z_{t}
$$

in which, $z_{t}$ is a sequence of random variables that are both independent and identically distributed (iid) and have zero mean and unit variance and the conditional variance $h_{t}$ is calculated as follows:

$$
h_{t}=a_{0}+a_{1} u^{2} t-1+a_{2} h_{t-1}
$$

In order to further investigate the cannabis equity market, we include in the above specification the daily investor attention on the stocks under review, as proxied by Google Trends (GTrend). The three-factor Fama and French (1993) model augmented with the liquidity and investors' attention measures is estimated as follows:

$$
\begin{aligned}
\mathrm{R}_{\mathrm{it}}-\mathrm{r}_{\mathrm{t}}=\beta_{\mathrm{i} 0}+ & \beta_{\mathrm{i} 1} \mathrm{R}_{\text {NAMMARt }}+\beta_{\mathrm{i} 2}\left(\mathrm{R}_{\mathrm{Mt}}-\mathrm{r}_{\mathrm{t}}\right)+\beta_{\mathrm{i} 3} \text { HML }_{\mathrm{t}}+\beta_{\mathrm{i} 4} \text { SMB }_{\mathrm{t}}+\beta_{\mathrm{i} 5} \% \mathrm{LIX}_{\mathrm{t}} \\
& +\beta_{\mathrm{i} 6} \% \text { LIX }_{\mathrm{t}-1}+\beta_{\mathrm{i} 7} \text { GTrend }_{\mathrm{t}}+\beta_{\mathrm{i} 8} \text { GTrend }_{\mathrm{t}-1}+\mathrm{u}_{\mathrm{it}}
\end{aligned}
$$

in which, GTrend is the Google Trends indicator for each stock $\mathrm{i}$. 
Finally, in order to allow for a feedback relationship between stock returns, liquidity and investor's attention we employ a VAR model in the following form:

$$
Y_{t}=a+A Y_{t-1}+\varepsilon_{t}
$$

in which, $\mathrm{Y}_{\mathrm{t}}$ is the vector containing vectors $\mathrm{y}$ of variables of the system (i.e., stock returns, liquidity and Google Trends indicator) and $\varepsilon_{\mathrm{t}}$ is the innovation vector. The optimal lag length is one under Schwarz and Hannan-Quinn information criteria. The impulse response function is calculated based on the $\mathrm{MA}(\infty)$ representation of the VAR model as follows:

$$
\mathrm{Y}_{\mathrm{t}}=\Phi(\mathrm{L}) \varepsilon_{\mathrm{t}}
$$

with $\Phi(\mathrm{L})$ denoting polynomial of the lag operator L. Values in $\Phi(\mathrm{L})$ are the impulse response coefficients, which we present as graphs in the following section.

\section{Results}

Figure 1 shows the time-series evolution of the stocks under study and the North American Marijuana (NAMMAR) Index, in which a significant drop is observed for the period of 2019-2020. Figure 1 also includes the evolution of the estimated liquidity measure, as well as the evolution of the Google search trend regarding cannabis stocks. Investors' attention, as proxied by Google search, topped at the end of 2018 and since then it has consistently declined, in line with the respective stock performance.

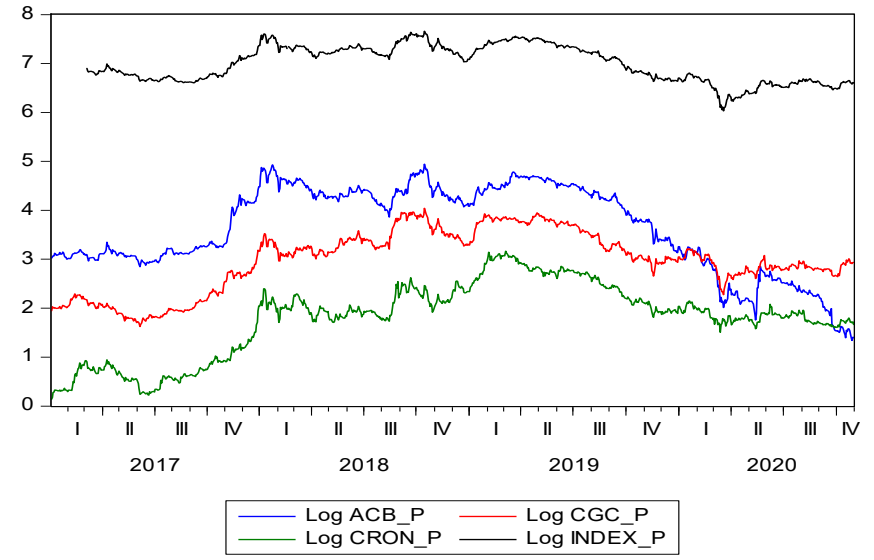

(a)

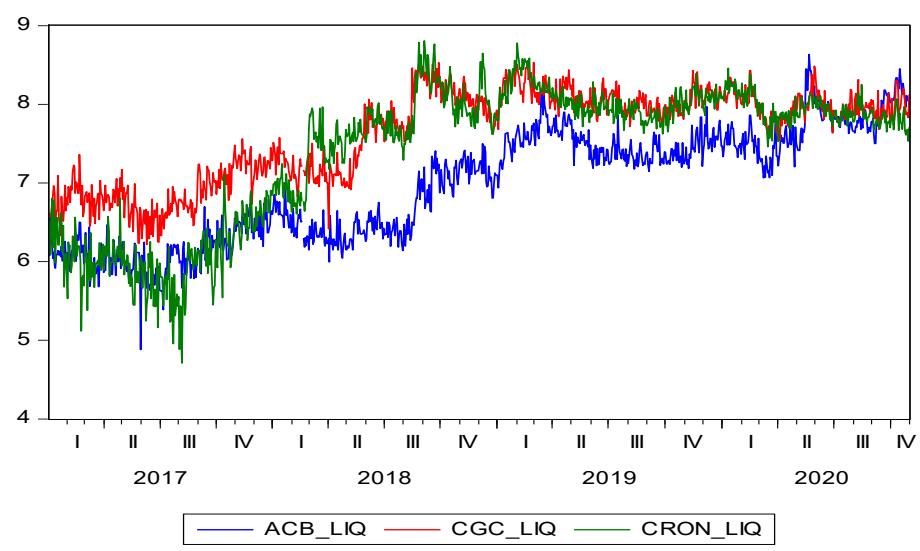

(b)

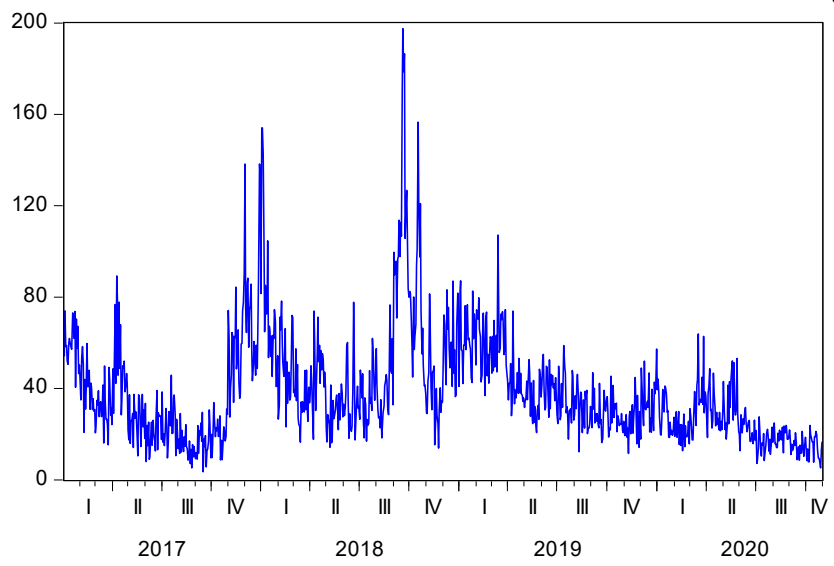

(c)

Figure 1. This figure presents the employed variables. (a) Stock and index historical prices (in logs); (b) liquidity measure; (c) Google Trends indicator regarding cannabis stock hits. 
The empirical results of the asset pricing models are included in Table 1 . The effect of market $\beta$ is positive, as expected, and significant, but its effect is essentially minimal—as measured by the size of the respective coefficients. It is apparent that cannabis stocks are affected by their sectoral index, as the coefficient for the NAMMAR Index is statistically significant at the 99\% level for all three stocks and hovers around 1.4. The other two Fama and French factors (size and value) are positive and statistically significant, verifying the appropriateness of the particular asset pricing model.

Table 1. Maximum likelihood estimations using symmetric generalized autoregressive conditional heteroscedasticity, GARCH $(1,1)$ model.

\begin{tabular}{|c|c|c|c|c|c|c|c|c|c|c|c|c|c|}
\hline & & \multicolumn{4}{|c|}{ ACB } & \multicolumn{4}{|c|}{ CGC } & \multicolumn{4}{|c|}{ CRON } \\
\hline \multicolumn{2}{|c|}{ Mean Equation } & \multicolumn{2}{|c|}{$\begin{array}{c}\text { FF-Model + } \\
\text { Liquidity }\end{array}$} & \multicolumn{2}{|c|}{$\begin{array}{c}\text { FF-Model + } \\
\text { Liquidity + } \\
\text { Google Trends }\end{array}$} & \multicolumn{2}{|c|}{$\begin{array}{c}\text { FF-Model + } \\
\text { Liquidity }\end{array}$} & \multicolumn{2}{|c|}{$\begin{array}{c}\text { FF-Model + } \\
\text { Liquidity + } \\
\text { Google Trends }\end{array}$} & \multicolumn{2}{|c|}{$\begin{array}{c}\text { FF-Model + } \\
\text { Liquidity }\end{array}$} & \multicolumn{2}{|c|}{$\begin{array}{c}\text { FF-Model + } \\
\text { Liquidity + Google } \\
\text { Trends }\end{array}$} \\
\hline & Variables & Coef. & Prob. & Coef. & Prob. & Coef. & Prob. & Coef. & Prob. & Coef. & Prob. & Coef. & Prob. \\
\hline$\beta_{0}$ & Intercept & -0.004 & 0.000 & -0.0067 & 0.000 & -0.001 & 0.272 & -0.002 & 0.203 & -0.003 & 0.010 & -0.003 & 0.000 \\
\hline$\beta_{1}$ & $\mathrm{R}_{\text {NAMMAR }}$ & 1.4551 & 0.000 & 1.451 & 0.000 & 1.398 & 0.000 & 1.403 & 0.000 & 1.337 & 0.000 & 1.304 & 0.000 \\
\hline$\beta_{2}$ & $\mathrm{R}_{\mathrm{M}}-\mathrm{r}$ & 0.009 & 0.000 & 0.009 & 0.000 & 0.009 & 0.000 & 0.0087 & 0.000 & 0.011 & 0.000 & 0.011 & 0.000 \\
\hline$\beta_{3}$ & HML & 0.004 & 0.000 & 0.004 & 0.000 & 0.002 & 0.027 & 0.002 & 0.031 & 0.002 & 0.179 & 0.002 & 0.000 \\
\hline$\beta_{4}$ & SMB & 0.004 & 0.009 & 0.004 & 0.006 & 0.008 & 0.000 & 0.008 & 0.000 & 0.004 & 0.049 & 0.005 & 0.000 \\
\hline$\beta_{5}$ & $\% \operatorname{LIX}(t)$ & 0.121 & 0.000 & 0.116 & 0.000 & 0.066 & 0.038 & 0.064 & 0.048 & 0.084 & 0.063 & 0.084 & 0.000 \\
\hline$\beta_{6}$ & $\% \operatorname{LIX}(t-1)$ & 0.148 & 0.000 & 0.147 & 0.000 & -0.034 & 0.399 & -0.034 & 0.401 & 0.068 & 0.059 & 0.066 & 0.000 \\
\hline$\beta_{7}$ & GTrend $(\mathrm{t})$ & & & 0.00012 & 0.045 & & & 0.0001 & 0.037 & & & 0.0001 & 0.000 \\
\hline$\beta_{8}$ & $\operatorname{GTrend}(\mathrm{t}-1)$ & & & -0.00004 & 0.563 & & & 0.000 & 0.631 & & & -0.0001 & 0.000 \\
\hline \multicolumn{14}{|c|}{$\begin{array}{l}\text { Variance } \\
\text { Equation }\end{array}$} \\
\hline$\alpha_{0}$ & Intercept & 0.000 & 0.000 & $2.6 \times 10^{-4}$ & 0.000 & $3.0 \times 10^{-4}$ & 0.000 & $3.3 \times 10^{-4}$ & 0.000 & $1.8 \times 10^{-4}$ & 0.000 & $1.4 \times 10^{-4}$ & 0.000 \\
\hline$\alpha_{1}$ & ARCH & 0.311 & 0.000 & 0.313 & 0.000 & 0.116 & 0.000 & 0.116 & 0.000 & 0.130 & 0.000 & 0.135 & 0.000 \\
\hline$\alpha_{2}$ & GARCH & 0.495 & 0.000 & 0.471 & 0.000 & 0.413 & 0.000 & 0.356 & 0.021 & 0.760 & 0.000 & 0.735 & 0.000 \\
\hline \multicolumn{14}{|c|}{ Diagnostics } \\
\hline & $\begin{array}{l}\text { Idjusted } \\
\text {-squared }\end{array}$ & $59 \%$ & & $60 \%$ & & $70 \%$ & & $71 \%$ & & $54 \%$ & & $55 \%$ & \\
\hline & likelihood & 1978.320 & & 1980.950 & & 2171.230 & & 2174.000 & & 1935.020 & & 1978.840 & \\
\hline & $Q(12)$ & & 0.880 & & 0.880 & & 0.710 & & 0.620 & & 0.580 & & 0.720 \\
\hline & Qsq(12) & & 0.900 & & 0.980 & & 0.530 & & 0.460 & & 0.940 & & 0.980 \\
\hline & $\mathrm{RCH}(1)$ & & 0.410 & & 0.720 & & 0.570 & & 0.610 & & 0.670 & & 0.240 \\
\hline
\end{tabular}

Notes: ACB indicates Aurora Cannabis Inc., CGC Canopy Growth Corp. and CRON Cronos Group Inc.. Probabilities in bold indicate statistical significance.

FF-Model + Liquidity model refers to the three-factor Fama and French (1993) model augmented with the liquidity measure:

$$
\begin{aligned}
\mathrm{R}_{\mathrm{it}}-\mathrm{r}_{\mathrm{t}}=\beta_{\mathrm{i} 0}+\beta_{\mathrm{i} 1} \mathrm{R}_{\text {NAMMARt }} & +\beta_{\mathrm{i} 2}\left(\mathrm{R}_{\mathrm{Mt}}-\mathrm{r}_{\mathrm{t}}\right)+\beta_{\mathrm{i} 3} \mathrm{HML}_{\mathrm{t}}+\beta_{\mathrm{i} 4} \mathrm{SMB}_{\mathrm{t}}+\beta_{\mathrm{i} 5} \% \mathrm{LIX}_{\mathrm{t}} \\
& +\beta_{\mathrm{i} 6} \% \mathrm{LIX}_{\mathrm{t}-1}+\mathrm{u}_{\mathrm{it}}
\end{aligned}
$$

in which, $R_{i t}$ is the daily return of stock $i(i=A C B, C G C, C R O N)$ on day $t, r_{t}$ is the risk-free rate of return, $R_{\text {NAMMAR }}$ is the daily return of the Marijuana Index, $R_{M}$ is the return of the market, SMB is the average return of the small-capitalized portfolios minus the average return of the large-capitalized portfolios, HML is the average return of the value portfolios minus the average return of the growth portfolios, while \%LIX is the first logarithmic difference of the liquidity measure (LIX) and $u_{i t}$ is the error term.

FF-Model + Liquidity + Google Trends refers to the three factor Fama and French (1993) model augmented with the liquidity and investors' attention measures:

$$
\begin{aligned}
\mathrm{R}_{\mathrm{it}}-\mathrm{r}_{\mathrm{t}}=\beta_{\mathrm{i} 0}+ & \beta_{\mathrm{i} 1} \mathrm{R}_{\text {NAMMARt }_{\mathrm{t}}}+\beta_{\mathrm{i} 2}\left(\mathrm{R}_{\mathrm{Mt}}-\mathrm{r}_{\mathrm{t}}\right)+\beta_{\mathrm{i} 3} \text { HML }_{\mathrm{t}}+\beta_{\mathrm{i} 4} \mathrm{SMB}_{\mathrm{t}}+\beta_{\mathrm{i} 5} \% \mathrm{LIX}_{\mathrm{t}} \\
& +\beta_{\mathrm{i} 6} \% \text { IIX }_{\mathrm{t}-1}+\beta_{\mathrm{i} 7} \text { GTrend }_{\mathrm{t}}+\beta_{\mathrm{i} 8} \text { GTrend }_{\mathrm{t}-1}+\mathrm{u}_{\mathrm{it}}
\end{aligned}
$$

in which, GTrend is the Google Trend indicator for each stock i. 
The standard Fama-French model ignores the liquidity component as is assumes that equity markets are frictionless and all stocks are perfectly liquid, but our empirical findings demonstrate that liquidity is priced in the market, as liquidity (\%LIX) has a positive and significant coefficient for all three stocks under review; for ACB it is statistically significant at the $99 \%$ level, while for CGC and CRON at the $95 \%$ and $90 \%$ levels respectively. The effect of liquidity remains positive and significant in all three stocks when we include investors' attention as an additional variable. Google searches are found to be statistically significant and positive suggesting that increased investors' attention leads to positive returns.

The results concerning the variance equation (also presented in Table 1 ) show that the coefficients of the ARCH effect $\left(\alpha_{1}\right)$ are statistically significant at $1 \%$ significance level in all cases. This finding suggests that news about volatility from the previous period has an explanatory power on current volatility. The coefficients of the lagged conditional variance $\left(\alpha_{2}\right)$ are also significantly different from zero, indicating volatility clustering in cannabis stock returns. The sum of the $\alpha_{1}$ and $\alpha_{2}$ coefficients is high in all models, suggesting that shocks to the conditional variance are highly persistent. The practical implication of this volatility clustering and persistence is that investors become more averse to holding cannabis stocks due to uncertainty.

Furthermore, since investors view upside and downside risks differently, with a preference for positively skewed returns, for robustness analysis, the augmented FamaFrench models have also been estimated using an asymmetric GARCH model, i.e., the exponential GARCH (EGARCH) model. The results are presented in Table 2. Regarding the statistical significance of coefficients, their signs and their magnitudes, the results are consistent with the previous findings in Table 1 using the symmetrical GARCH. These results imply that the liquidity factor and investor attention (via Google Trends) contribute to the explanatory power of an asset pricing model in cannabis stocks.

Table 2. Maximum likelihood estimations using asymmetric EGARCH(1,1) model.

\begin{tabular}{|c|c|c|c|c|c|c|c|c|c|c|c|c|c|}
\hline & & \multicolumn{4}{|c|}{ ACB Company } & \multicolumn{4}{|c|}{ CGC Company } & \multicolumn{4}{|c|}{ CRON Company } \\
\hline \multicolumn{2}{|c|}{ Mean Equation } & \multicolumn{2}{|c|}{$\begin{array}{c}\text { FF-Model + } \\
\text { Liquidity }\end{array}$} & \multicolumn{2}{|c|}{$\begin{array}{c}\text { FF-Model + } \\
\text { Liquidity + } \\
\text { Google Trends }\end{array}$} & \multicolumn{2}{|c|}{$\begin{array}{c}\text { FF-Model + } \\
\text { Liquidity }\end{array}$} & \multicolumn{2}{|c|}{$\begin{array}{c}\text { FF-Model + } \\
\text { Liquidity + } \\
\text { Google Trends }\end{array}$} & \multicolumn{2}{|c|}{$\begin{array}{c}\text { FF-Model + } \\
\text { Liquidity }\end{array}$} & \multicolumn{2}{|c|}{$\begin{array}{c}\text { FF-Model + } \\
\text { Liquidity + Google } \\
\text { Trends }\end{array}$} \\
\hline & Variables & Coef. & Prob. & Coef. & Prob. & Coef. & Prob. & Coef. & Prob. & Coef. & Prob. & Coef. & Prob. \\
\hline$\beta_{0}$ & Intercept & -0.0023 & 0.000 & -0.0048 & 0.000 & -0.001 & 0.234 & -0.002 & 0.203 & -0.003 & 0.010 & -0.003 & 0.000 \\
\hline$\beta_{1}$ & $\mathrm{R}_{\text {NAMMAR }}$ & 1.45096 & 0.000 & 1.4446 & 0.000 & 1.400 & 0.000 & 1.304 & 0.000 & 1.337 & 0.000 & 1.304 & 0.000 \\
\hline$\beta_{2}$ & $\mathrm{R}_{\mathrm{M}}-\mathrm{r}$ & 0.009 & 0.000 & 0.009 & 0.000 & 0.008 & 0.000 & 0.010 & 0.000 & 0.011 & 0.000 & 0.011 & 0.000 \\
\hline$\beta_{3}$ & HML & 0.004 & 0.000 & 0.004 & 0.000 & 0.0014 & 0.064 & 0.001 & 0.000 & 0.002 & 0.179 & 0.002 & 0.000 \\
\hline$\beta_{4}$ & SMB & 0.004 & 0.007 & 0.004 & 0.005 & 0.008 & 0.000 & 0.004 & 0.000 & 0.004 & 0.049 & 0.005 & 0.000 \\
\hline$\beta_{5}$ & $\% \operatorname{LIX}(t)$ & 0.127 & 0.000 & 0.125 & 0.000 & 0.067 & 0.045 & 0.078 & 0.000 & 0.084 & 0.063 & 0.084 & 0.000 \\
\hline$\beta_{6}$ & $\% \operatorname{LIX}(t-1)$ & 0.180 & 0.000 & 0.177 & 0.000 & -0.045 & 0.240 & -0.034 & 0.000 & 0.068 & 0.059 & 0.066 & 0.000 \\
\hline$\beta_{7}$ & GTrend $(t)$ & & & 0.00015 & 0.013 & & & 0.0006 & 0.000 & & & 0.0001 & 0.000 \\
\hline$\beta_{8}$ & $\left.\operatorname{GTrend}_{\mathrm{t}-1}\right)$ & & & -0.00007 & 0.206 & & & -0.0007 & 0.000 & & & -0.0001 & 0.000 \\
\hline \multicolumn{14}{|c|}{$\begin{array}{l}\text { Variance } \\
\text { Equation }\end{array}$} \\
\hline$\alpha_{0}$ & Intercept & -1.6743 & 0.000 & -1.691 & 0.000 & -3.967 & 0.000 & -0.732 & 0.000 & $1.8 \times 10^{-4}$ & 0.000 & $1.4 \times 10^{-4}$ & 0.000 \\
\hline$\alpha_{1}$ & $\mathrm{ARCH}$ & 0.496 & 0.000 & 0.497 & 0.000 & 0.267 & 0.000 & 0.194 & 0.000 & 0.130 & 0.000 & 0.135 & 0.000 \\
\hline$\alpha_{2}$ & GARCH & 0.048 & 0.030 & 0.048 & 0.046 & -0.019 & 0.000 & 0.064 & 0.030 & 0.760 & 0.000 & 0.735 & 0.000 \\
\hline$\alpha_{2}$ & GARCH & 0.810 & 0.000 & 0.808 & 0.000 & 0.489 & 0.000 & 0.941 & 0.000 & 0.760 & 0.000 & 0.735 & 0.000 \\
\hline \multicolumn{14}{|c|}{ Diagnostics } \\
\hline & $\begin{array}{l}\text { dijusted } \\
\text {-squared }\end{array}$ & $59 \%$ & & $60 \%$ & & $71 \%$ & & $55 \%$ & & $54 \%$ & & $55 \%$ & \\
\hline & likelihood & 1974.330 & & 1977.056 & & 2170.240 & & 1978.212 & & 1935.020 & & 1978.840 & \\
\hline & $\mathrm{Q}(12)$ & & 0.860 & & 0.860 & & 0.760 & & 0.730 & & 0.580 & & 0.720 \\
\hline & Qsq(12) & & 0.700 & & 0.670 & & 0.470 & & 0.980 & & 0.940 & & 0.980 \\
\hline & RCH(1) & & 0.320 & & 0.291 & & 0.470 & & 0.410 & & 0.670 & & 0.240 \\
\hline
\end{tabular}

Notes: ACB indicates Aurora Cannabis Inc., CGC Canopy Growth Corp. and CRON Cronos Group Inc.. Probabilities in bold indicate statistical significance. 
In concluding our empirical analysis, we present a generalized impulse response function in vector autoregressive (VAR) models studying the response of cannabis stock returns to shocks to investors' attention (Figure 2) and liquidity (Figure 3). In particular, a shock transmission between the variables under consideration appears in the impulse response analysis originated by the VAR model estimation. The respective figures demonstrate clearly the short-term positive effect that Google search stock hits have on stock returns. The positive relationship of liquidity and returns that is documented in the asset pricing models above is also confirmed by the impulse response analysis, suggesting a positive liquidity premium.

Response of DLOG(ACB_P) to STOCK_HITS Response of DLOG(CGC_P) to STOCK_HITS


Figure 2. Impulse response function (investors' attention $\rightarrow$ returns). This figure includes the generalized impulse response function in vector autoregressive (VAR) models studying the response of cannabis stock returns to shocks to investors' attention. 


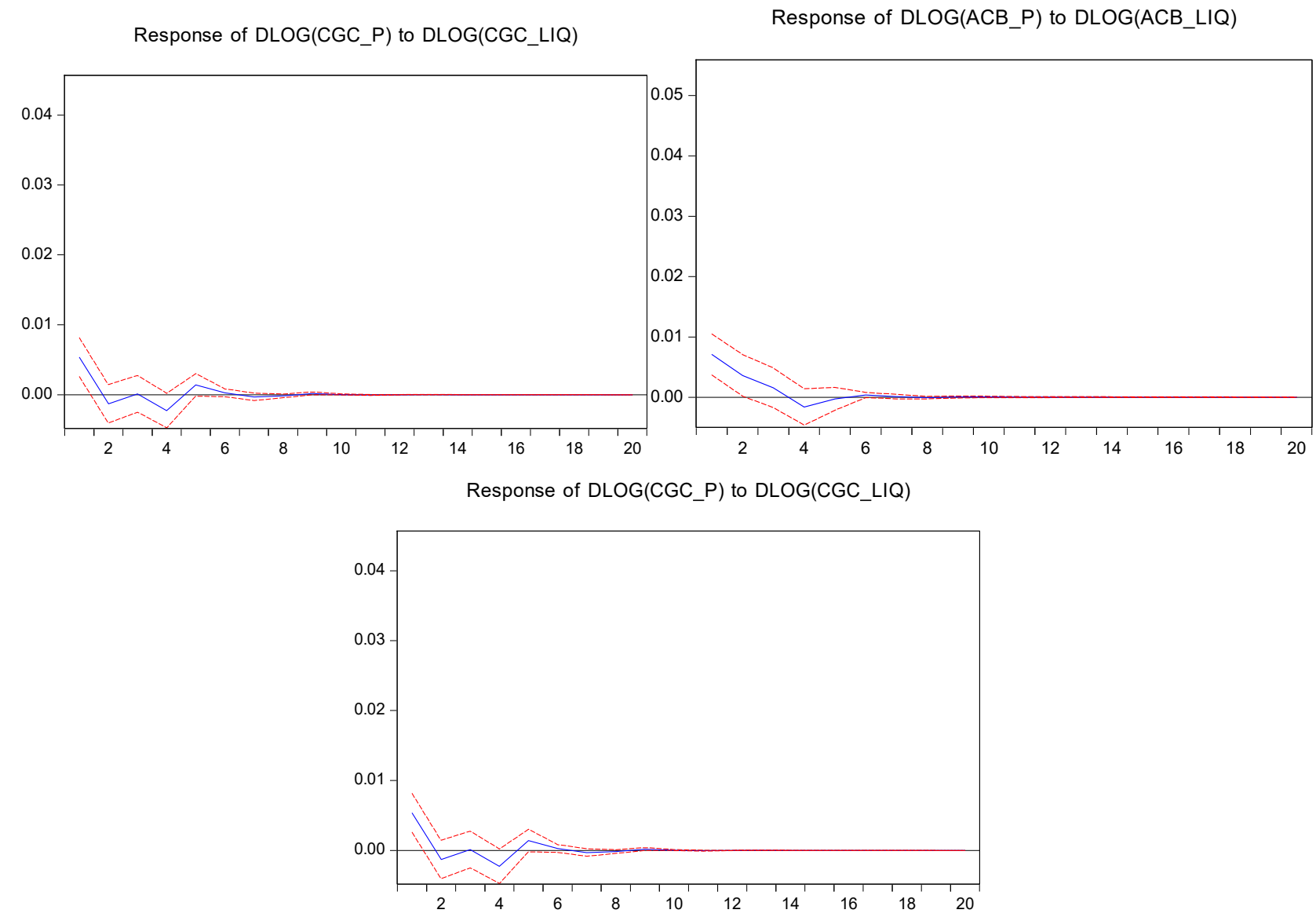

Figure 3. Impulse response function (liquidity $\rightarrow$ returns). This figure includes the generalized impulse response function in vector autoregressive (VAR) models studying the response of cannabis stock returns to shocks liquidity.

\section{Conclusions}

In our empirical analysis we employ a direct measure of investor attention via Google search intensity and study its relationship with returns and liquidity regarding certain cannabis stocks. To the best of our knowledge, this paper provides the first relevant evidence for a fast-growing new sector in equity markets.

In particular, we utilize the three-factor Fama and French (1993) model augmented with liquidity and investors' attention to study the relationship between investor sentiment, as proxied by liquidity and Google search trends, and cannabis stocks returns. The assetpricing results indicate a positive relationship between returns and liquidity. Furthermore, the importance of liquidity remains significant even after controlling for the role of investor sentiment. Finally, the impulse response function, which is a simple, yet powerful tool for studying the dynamic transmission of shocks and/or innovations shows that there is a positive dependence between returns and liquidity in the cannabis sector.

Understanding the links between investors' attention and asset price dynamics is critical for designing and implementing the policy measures needed in markets and economies. Nowadays, investors can extract information from Google trends and at the same time take active trading decisions, as the use of technology in investment decisions is growing exponentially. In addition, documenting the relationship between returns and liquidity enhances any policy or risk management practices.

In conclusion, we use two specific proxies for investors' attention and liquidity: Google Trends and a volume-based measure, respectively. Since there is no consensus within existing empirical literature on the measurement of these two variables, other dimensions of investors' attention (such as news-based measures, or information from social networks 
and/or stock trading platforms) and liquidity (such as spread-based or price-based measures) can be employed. Finally, we use daily data, but future research can consider data at different frequencies.

Author Contributions: Conceptualization, S.P., A.K., C.K. and A.P.F.; methodology, S.P., A.K., C.K. and A.P.F.; writing-original draft preparation, S.P., A.K., C.K. and A.P.F.; writing-review and editing, S.P., A.K., C.K. and A.P.F.; visualization, S.P., A.K., C.K. and A.P.F. All authors have read and agreed to the published version of the manuscript.

Funding: This research received no external funding.

Institutional Review Board Statement: Not applicable.

Informed Consent Statement: Not applicable.

Data Availability Statement: The data presented in this study are available on request from the corresponding author.

Conflicts of Interest: The authors declare no conflict of interest.

\section{References}

Acharya, Vital V., and Lasse Heje Pedersen. 2005. Asset pricing with liquidity risk. Journal of Financial Economics 77: 375-410. [CrossRef] Akhtaruzzaman, Md, Sabri Boubaker, and Zaghum Umar. 2021. COVID-19 media coverage and ESG leader indices. Finance Research Letters, 102170, in press. [CrossRef]

Amihud, Yakov, and Haim Mendelson. 1986. Asset pricing and the bid-ask spread. Journal of Financial Economics 17: 223-49. [CrossRef]

Amihud, Yakov, Allaudeen Hameed, Wenjin Kang, and Huiping Zhang. 2015. The illiquidity premium: International evidence. Journal of Financial Economics 117: 350-68. [CrossRef]

Amihud, Yakov. 2002. Illiquidity and stock returns: Cross-section and time series effects. Journal of Financial Markets 5: 31-56. [CrossRef]

Andrikopoulos, Panagiotis, Bartosz Gebka, and Vasileios Kallinterakis. 2021. Regulatory mood-congruence and herding: Evidence from cannabis stocks. Journal of Economic Behavior \& Organization 185: 842-64.

Assoil, Ayad, Ndéné Ka, and Jules Sadefo-Kamdem. 2021. Analysis of the dynamic relationship between liquidity proxies and returns on the French CAC 40 index. SN Business E Economics 1: 1-23.

Bahji, Anees, and Callum Stephenson. 2019. International perspectives on the implications of cannabis legalization: A systematic review \& thematic analysis. International Journal of Environmental Research and Public Health 16: 3095.

Boubaker, Sabri, Dimitrios Gounopoulos, and Hatem Rjiba. 2019. Annual report readability and stock liquidity. Financial Markets, Institutions $\mathcal{E}$ Instruments 28: 159-86.

Brennan, Michael, and Avanidhar Subrahmanyam. 1996. Market microstructure and asset pricing: On the compensation for illiquidity in stock returns. Journal of Financial Economics 41: 441-64. [CrossRef]

Carrière-Swallow, Yan, and Felipe Labbé. 2013. Nowcasting with Google Trends in an emerging market. Journal of Forecasting 32: 289-98. [CrossRef]

Chen, Feilong, Sungchul Choi, Chengbo Fu, and Joshua Nycholat. 2021. Too high to get it right: The effect of cannabis legalization on the performance of cannabis-related stocks. Economic Analysis and Policy 72: 715-34. [CrossRef]

Chiang, Thomas C., and Dazhi Zheng. 2015. Liquidity and stock returns: Evidence from international markets. Global Finance Journal 27: 73-97. [CrossRef]

Choi, Hyunyoung, and Hal Varian. 2012. Predicting the present with Google Trends. Economic Record 88: 2-9. [CrossRef]

Chronopoulos, Dimitris K., Fotios I. Papadimitriou, and Nikolaos Vlastakis. 2018. Information demand and stock return predictability. Journal of International Money and Finance 80: 59-74. [CrossRef]

Da, Zhi, Joseph Engelberg, and Pengjie Gao. 2011. In search of attention. The Journal of Finance 66: 1461-99. [CrossRef]

Da, Zhi, Joseph Engelberg, and Pengjie Gao. 2015. The sum of all FEARS investor sentiment and asset prices. The Review of Financial Studies 28: 1-32. [CrossRef]

Danyliv, Oleh, Bruce Bland, and Daniel Nicholass. 2014. Convenient Liquidity Measure for Financial Markets. Available online: https: / / ssrn.com/abstract=2385914 (accessed on 27 January 2014).

Dimpfl, Thomas, and Stephan Jank. 2016. Can internet search queries help to predict stock market volatility? European Financial Management 22: 171-92. [CrossRef]

Ding, Rong, and Wenxuan Hou. 2015. Retail investor attention and stock liquidity. Journal of International Financial Markets, Institutions and Money 37: 12-26. [CrossRef]

Drake, Michael S., Darren T. Roulstone, and Jacob R. Thornock. 2012. Investor information demand: Evidence from Google searches around earnings announcements. Journal of Accounting Research 50: 1001-40. [CrossRef]

Eckstein, Zvi, and Daniel Tsiddon. 2004. Macroeconomic consequences of terror: Theory and the case of Israel. Journal of Monetary Economics 51: 971-1002. [CrossRef] 
Fama, Eugene, and Kenneth French. 1993. Common Risk Factors in the Returns on Stocks and Bonds. Journal of Financial Economics 33: 3-56. [CrossRef]

Ginsberg, Jeremy, Matthew H. Mohebbi, Rajan S. Patel, Lynnette Brammer, Mark S. Smolinski, and Larry Brilliant. 2009. Detecting influenza epidemics using search engine query data. Nature 457: 1012-14. [CrossRef]

Goddard, John, Arben Kita, and Qingwei Wang. 2015. Investor attention and FX market volatility. Journal of International Financial Markets, Institutions and Money 38: 79-96. [CrossRef]

Hasbrouck, Joel. 2009. Trading costs and returns for US equities: Estimating effective costs from daily data. Journal of Finance 64: 1445-77. [CrossRef]

Joseph, Kissan, M. Babajide Wintoki, and Zelin Zhang. 2011. Forecasting abnormal stock returns and trading volume using investor sentiment: Evidence from online search. International Journal of Forecasting 27: 1116-27. [CrossRef]

Kyriazis, Nikolaos, and Paraskevi Prassa. 2019. Which Cryptocurrencies Are Mostly Traded in Distressed Times? Journal of Risk and Financial Management 12: 135. [CrossRef]

Lang, Mark, Karl Lins, and Mark Maffett. 2012. Transparency liquidity and valuation: International evidence on when transparency matters most. Journal of Accounting Research 50: 729-74. [CrossRef]

Lee, Kuan-Hui. 2011. The world price of liquidity risk. Journal of Financial Economics 99: 136-61. [CrossRef]

Leirvik, Thomas, Sondre R. Fiskerstrand, and Anders B. Fjellvikås. 2017. Market liquidity and stock returns in the Norwegian stock market. Finance Research Letters 21: 272-76. [CrossRef]

Liu, Weimin. 2006. A liquidity-augmented capital asset pricing model. Journal of Financial Economics 82: 631-71. [CrossRef]

Metaxas, P. T., and E. Mustafaraj. 2012. Social media and the elections. Science 338: 472-73. [CrossRef]

Mondria, Jordi, Thomas Wu, and Yi Zhang. 2010. The determinants of international investment and attention allocation: Using internet search query data. Journal of International Economics 82: 85-95. [CrossRef]

Padungsaksawasdi, Chaiyuth, Sirimon Treepongkaruna, and Robert Brooks. 2019. Investor Attention and Stock Market Activities: New Evidence from Panel Data. International Journal of Financial Studies 7: 30. [CrossRef]

Papadamou, Stephanos, Athanasios P. Fassas, Dimitris Kenourgios, and Dimitrios Dimitriou. 2020. Direct and Indirect Effects of COVID-19 Pandemic on Implied Stock Market Volatility: Evidence from Panel Data Analysis. Munich Personal RePEc Archive (MPRA). Paper No. 100020. May. Available online: https://mpra.ub.uni-muenchen.de/100020/ (accessed on 18 November 2021).

Papadamou, Stephanos, Athanasios P. Fassas, Dimitris Kenourgios, and Dimitrios Dimitriou. 2021. Flight-to-quality between global stock and bond markets in the COVID era. Finance Research Letters 38: 101852. [CrossRef]

Parker, Karen A., Attilio Di Mattia, Fatima Shaik, Juan Carlos Cerón Ortega, and Robert Whittle. 2019. Risk management within the cannabis industry: Building a framework for the cannabis industry. Financial Markets, Institutions E Instruments 28: 3-55.

Polgreen, Philip M., Yiling Chen, David M. Pennock, Forrest D. Nelson, and Robert A. Weinstein. 2008. Using internet searches for influenza surveillance. Clinical Infectious Diseases 47: 1443-48. [CrossRef] [PubMed]

Polykalas, Spyros E., George N. Prezerakos, and Agisilaos Konidaris. 2013. An algorithm based on Google Trends' data for future prediction. Case study: German elections. Paper presented at IEEE International Symposium on Signal Processing and Information Technology, Athens, Greece, December 12-15; pp. 69-73. [CrossRef]

Poutachidou, Nikoletta, and Stephanos Papadamou. 2021. The Effect of Quantitative Easing through Google Metrics on US Stock Indices. International Journal of Financial Studies 9: 56. [CrossRef]

Preis, Tobias, Helen Susannah Moat, and H. Eugene Stanley. 2013. Quantifying trading behavior in financial markets using Google Trends. Scientific Reports 3: 1684. [CrossRef] [PubMed]

Smith, Geoffrey Peter. 2012. Google Internet search activity and volatility prediction in the market for foreign currency. Finance Research Letters 9: 103-10. [CrossRef]

Vlastakis, Nikolaos, and Raphael N. Markellos. 2012. Information demand and stock market volatility. Journal of Banking E Finance 36: 1808-21.

Vozlyublennaia, Nadia. 2014. Investor attention, index performance, and return predictability. Journal of Banking E Finance 41: 17-35.

Weisskopf, Jean-Philippe. 2020. Breaking bad: An investment in cannabis. Finance Research Letters 33: 101201. [CrossRef]

Yang, Ann Shawing, and Airin Pangastuti. 2016. Stock market efficiency and liquidity: The Indonesia Stock Exchange merger. Research in International Business and Finance 36: 28-40. [CrossRef] 